\title{
研究論文
}

\section{0. 焦点クロマトグラフ法による希土類元素の分離}

\author{
亀本雄一郎*,萩谷公子*, 山岸 滋* \\ Separation of Rare Earth Elements by Focussing Chromatography \\ By Yuichiro KAMEMOTO, \\ Kimiko HAGIYA and Shigeru YAMAGISHI
}

\begin{abstract}
Focussing chromatography was applied to the mutual separation of rare earth elements and the effect of several conditions upon the separation of rare earth elements was studied. The most satisfactory result was obtained in the conditions as follows: $0.1 \mathrm{M}$ citric acid was used as the complexing agent and $0.01 \mathrm{~N}$ hydrochloric acid as the decomplexing agent, $\mathrm{pH}$ gradient of both solutions between anode and cathode was $\mathrm{pH}$ $2.8(\mathrm{HCl})-4.4$ (citric acid), the rare earth solutions contained no nitric acid, the applied voltage was $1,000 \mathrm{~V} / 30 \mathrm{~cm}$, the treatment time was $20 \mathrm{~min}$, and the filter paper was Toyo Roshi No. 50.

After treatment of separation, the autoradiographic technique was employed to decide the position of each separated line.
\end{abstract}

\section{I. 緒言}

希土類元素の放射化分析についてはすでにいくつか の報告(3)がなされている。しかし，いずれる希土類元 素相互の分離が困難であるため，照射条件，測定条件 を変化させたり，買変曲線を解析したりすることによ りいくつかの希土類元素を定量しているに過ぎない。 希土類元素はいずれも放射化断面積が大きいので，相 互の分離法が完成されれば個々の定量が可能と考えら れる。

従来希土類元素の分離には，主としてイオン交換樹 脂法 ${ }^{(2)}$ が満足のいく方法として探用されているが，本 法による希土類元素の分離は割合い長時間を要し，放 射化分析に用いるには必ずしす適当でない。一方，近 年焦点クロマトグラフ法(3)が痕跡量の元素のすぐれた 分離法として開発されているが, Schumacher ら ${ }^{(4)}$ の 研究により希土類元素の分離に本法の適用が最近可能 となった。

著者らは本法の放射化分析法への適用を検討してき たが，さらに希土類元素の担体を用いた場合にも本法 による分離が可能となるように沪紙パイル，棒状沪紙 などの使用の検討を試みた。今回はこの基脴研究であ
る通常のペーパークロマトグラフ用汇紙を用いた希土 類元素の相互分離について報告する。

\section{II. 試薬・装 置}

\section{1. トレーサ溶夜}

横沢化学㑣製の各希土類酸化物 $2 \mathrm{mg}$ 光 JRR-1 原子 炉中で, 中性子束 $3 \times 10^{11} \mathrm{n} / \mathrm{cm}^{2} /$ see て $2 \mathrm{hr}$ なは3 日間( 1 日最大 $5 \mathrm{hr}$ ) 中性子照射を行な5。照射後でき るだけ少量の濃硝酸にとかし，塩酸ととるに加熱して 硝酸を除去する。蒸発残査を水にとかし水酸化ナトリ ウムと塩酸の希溶液で $\mathrm{pH} を 2$ に調節して $25 \mathrm{ml}$ まで 希秎する。ユーロピウムはさらに 1/100k希积したる のを使用した。

\section{2. 試 蒋}

（1）錯化剤：0.1 Mクエン酸溶液を調節し， $\mathrm{pH}$ 調節 は水酸化ナトリウムと塭酸の希溶腹を用いた。

（2）塩酸：陽極側に使用する塩酸は $0.1 〜 0.001 \mathrm{~N} の$ 範囲のるのを種々調製し， $\mathrm{pH}$ を水酸化ナトリウ ムの希溶液を用いて調節した。

（3）四塩化炭素: 冷却剂として四塩化炭素の特級品

* 日本原子力研究所, 化学部(Div. Chem., Japan Atomic Energy Res. Inst.) 
を使用した。

3. 沪紙

ペーパークロマトグラフ用東洋汇紙 No. 50 (幅 2

$\mathrm{cm}$ ，長さ $35 \mathrm{~cm}$ に切断)を使用した。

4. 装 是

分雜装置は東洋沪紙侏製電気泳動装置を使用した。 直流電源部 $(1,500 \mathrm{~V}, 100 \mathrm{~mA})$ と泳動槽からなり, 泳動畨の沪紙は四塩化炭素で冷却される。第 1 図に概 略の泳動槽の図を示す。

$\mathrm{pH}$ 湘定には柳本製作所製ガラス電極 $\mathrm{pH}$ メータを 使用した。

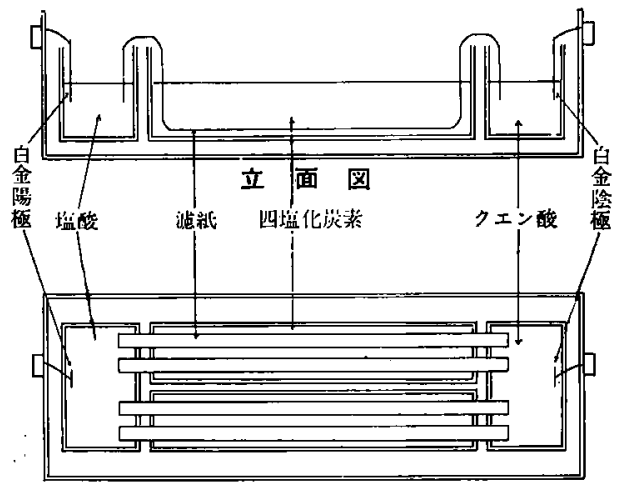

平面图

第 1 図泳動 榑

\section{II. 分 離}

\section{1. 分離操作}

クロマトグラフ用沪紙の中央部に印をつけ，トレー サ溶液 $0.1 \mathrm{~m} l$ をミクロピペットで塗着する。この試料 塗着带の陽極側は塩酸で，陰極側はクエン酸溶液で一 様に浸した後，過剩の液を別の大型の沪紙でふきと る。つぎに，第 1 㘡炕見られるよ5に両極間の洰紙の 長さが約 $30 \mathrm{~cm}$ になるよ 5 に泳動槽中にこの沪紙片を
セットし( 1 度に 4 枚セット可能), $1,000 \mathrm{~V} / 30 \mathrm{~cm} て ゙$ $5 \sim 25 \mathrm{~min}$ 間通電した。通電後洰紙片を泳動槽から 取り外ずし，直ちに赤外線ランプ下で乾燥した。洰紙 上の各核種の分離線の位置は富士X線フィルムによる オートラジオグラムから決定した。

\section{2. 最適条件}

はじめに各トレーサを単独に用いていろいろな条件

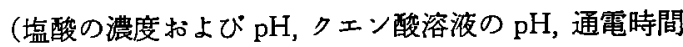
など)下で分離線の位置を決定し，各分離線が相互に 最もよく分かれる条件を決定した。この結果. トレー サ溶液は硝酸根不在の状態にして $\mathrm{pH} 2$ に調節し，陽 極側に $\mathrm{pH} 2.8$ に調節した $0.01 \mathrm{~N}$ 塩酸。陰極側に $\mathrm{pH}$ 4.4 に調節した $0.1 \mathrm{M} ク$ クン酸溶夜を使用し，通電時 間20〜25 min で最良の分離を示すことが明らかとな った。次節以下にこの検討結果を報告する。

\section{IV. 実 験 結 果}

\section{1. トレーサ溶液の硝酸根の影響}

希土類酸化物は硝酸にとかして溶液とするので，卜 レーサ溶液に硝酸酸性溶液を用いることができれば極 めて好都合である。 $\mathrm{pH}$ があまり低いものであれば， 当然 $\mathrm{pH}$ 勾配を乱して满足のいく分離線が得られない と考えられる。著者らはトレーサ溶液として，濃硝酸 性の6の，希硝酸溶液の $\mathrm{pH}$ を水酸化ナトリウムに上 り 2 に調節したすの，塩酸酸性溶液に硝酸ナトリウム を加えて $\mathrm{pH}$ を 2 に調節したすの，を使用して硝酸根 の影響を調べた。陽極側に $\mathrm{pH} 2.8$ の $0.01 \mathrm{~N}$ 塩酸，陰 極側に $\mathrm{pH} 4.4$ の0.1 M クエン酸溶夜を使用し，各トレ 一サ溶液を塗布後 $1,000 \mathrm{~V} / 30 \mathrm{~cm}, 20 \mathrm{~min}$ 間の通電を 行なった。その結果をまとめて第 2 図に示す。この図 からわかるように明らかに硝酸根は分離に影響を与 え，その存在は望ましくないことがわかった。したが

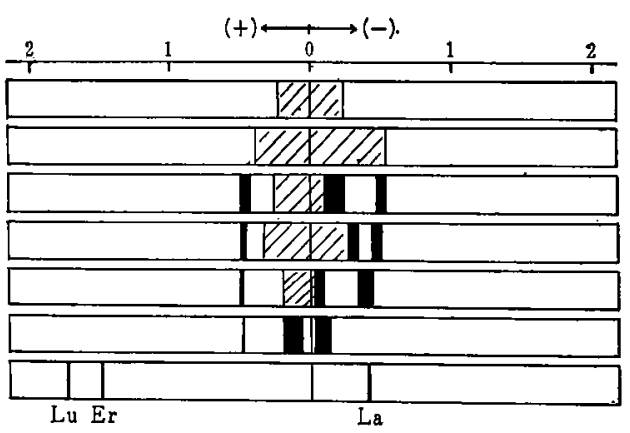

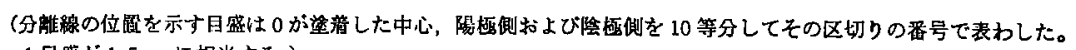
1 目盛が $1.5 \mathrm{~cm}$ К相当する。

第 2 図分離線に及はす硝酸根の影響 
って，以後硝酸根は塩酸ととひに加熱することにより 完全に除去すをことにした。

\section{2. 錯化剂の $\mathrm{pH}$ 值が分離線に及ぼす影響}

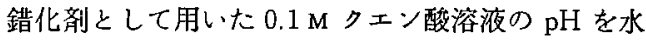
酸化ナトリウム拈よび塩酸で種々に変え，分離線の位 置と $\mathrm{pH}$ の関係を調ぺた。すなわち，塩酸の摵度0.01、 0.05, $0.1 \mathrm{~N}$ についてクエン酸の $\mathrm{pH}$ を種々に変えて分 離線の位置を調へた。その 1 例を第 3 図に示す。

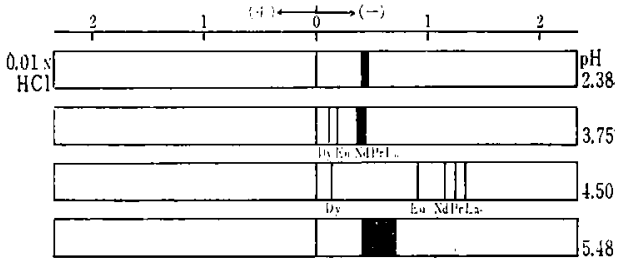

第3図クェン酸の $\mathrm{pH}$ によ 分離線の位置の变化

検討の結果，クエン酸の $\mathrm{pH} 4.5$ 付近で最もよい分 離を示したので，以後 $\mathrm{pH}$ を 4.4 に調節した。

3. 陽極側の塩酸溶液の $\mathrm{pH}$ 值が分離に及ぼす影響 分離に大きな影響を与える陽極側の塩酸溶液の $\mathrm{pH}$

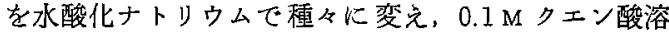
液( $\mathrm{pH}$ 4.4) との間で通電を行ない，最適の $\mathrm{pH}$ 值を検 討した。1例を第 4図に示す。この図からもかかるよ $5 に \mathrm{pH} 2.8$ の時が最も良好な結果を示した。

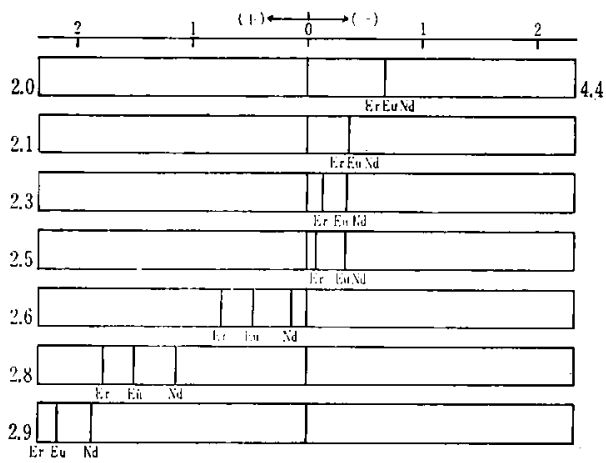

第 4図 塩酸の $\mathrm{pH}$ にる分離線の位置の変化

\section{4. 通電時間の検討}

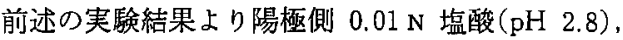
陰極側 $0.1 \mathrm{M}$ クエン酸 $(\mathrm{pH}$ 4.4)の $\mathrm{pH}$ 勾配の時最良の 分離を示したので，この条件で通電時間を変えて分離 線の移動孛調べた。1 例第 5 図に示す。

通電時間 $5 \sim 15 \min$ の間比較的分離線の移動が早 く，20〜25 minではほほ同一の位監に分離線を示す。 したがって，通電時間として $20 \mathrm{~min}$ 間を採用した。

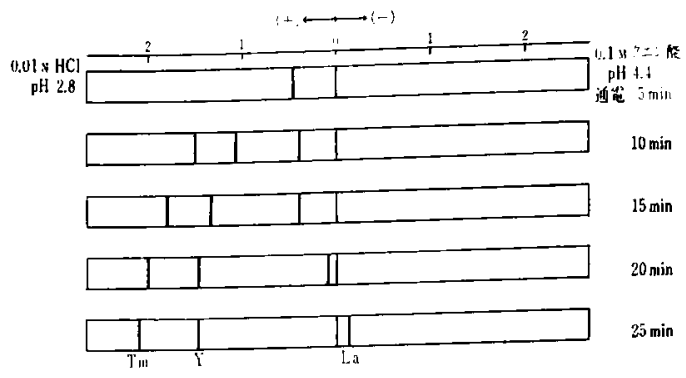

第 5 図分離線に及ほす通電時間の影響

5. $\mathrm{pH}$ 勾配

通電時間の変化ととも: $\mathrm{pH}$ 勾配がいか変化する かを $\mathrm{pH}$ 試験紙を用いて検討した。すなおち、トレー サを塗布しない、汇紙片の一端を0.01 N 塩酸( $\mathrm{pH} 2.8) の$ 液に，他端を $0.1 \mathrm{M} ク エ ン$ 酸 $(\mathrm{pH} 4.4)$ の液にそれぞれ 浸して通電を行なった。通電時間を $5 〜 20 \mathrm{~min}$ 変化 し，沪紙片の種々な位置に $\mathrm{pH}$ 試験紙の小片をつけて それぞれの $\mathrm{pH}$ 值を求めてみた。結果を第 6 図に示 す。 $5 \sim 20 \mathrm{~min} て ゙ は$ 通電時間によって目立つ変化は見 られなかった。

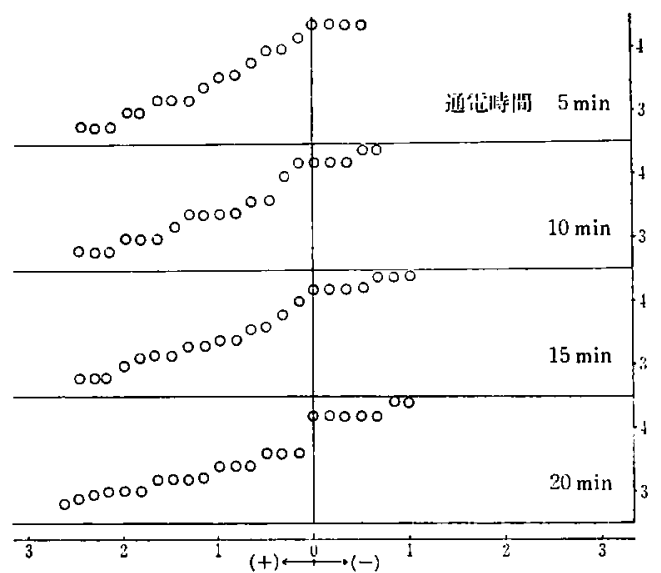

第 6 図通電時間による $\mathrm{pH}$ 勾配の変化

\section{6. 分離線の位置}

陽極側 $0.01 \mathrm{~N}$ 塩醉 $(\mathrm{pH} 2.8$ ), 陰極側 $0.1 \mathrm{M}$ クエン酸 (pH 4.4)，通電時間 $20 \mathrm{~min}$ ，加電圧 $1,000 \mathrm{~V}$ の条件て 1 種ずつのトレーサを用いて分離線の位置を求めた。 結果を第 7 図に示す。微小な条件の差により分離線の 位置がやや異なって現われるか，全体を見ると分離楾 の位置は，瓜土類元素のクエン酸錯塩の安定度に従っ て䎫化し，異常は見られなかっ心

希土類元素が重くなるに従って分離楾の位置の差が 少なくなり，分離楾の間隔が軽いちにくらべてせまく なる。 


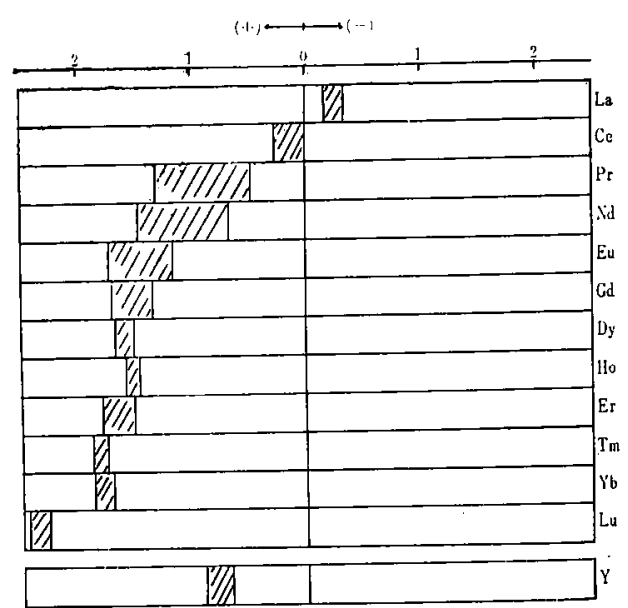

（数回の実駼をくり返し分嚾線の位置が斜線内に 入ることを示す。)

第 7 図各トレーサの分離線の位置

\section{7. 分離例}

前述の上うにして分離の最適条件が決定されたの で，トレーサの種々混合液を用いて分離を試みた。2 〜 6 種のトレーサ混合溶液 $0.1 \mathrm{ml}$ を用い, 上記の分析 操作に從って分離を行なったいくつかの例を第 8 図に 示す。

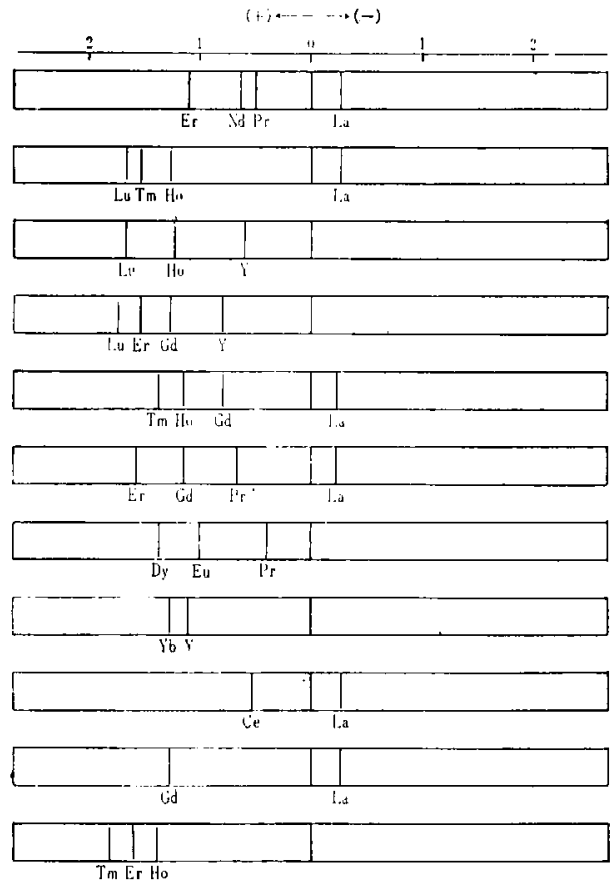

第 8 図希土類混合物の分離例

\section{、. 考察}

上述の方法により希土類元素相互の分離が可能なこ とが明らかとなった。この各希土類元素の分離線の位 置は毎回の実験で多少のズがあり(第 7 図)，そのつ どオートラジオグラフにより位置を確かめねばならな い。この位置のズレは各液の $\mathrm{pH}$, 通電時間, 加電圧な とのわずかの差異に起因すると考えられる。

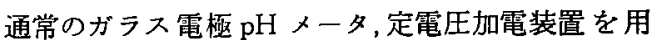
いる場合には，どうしてる多少のズレはさけえなかっ た。

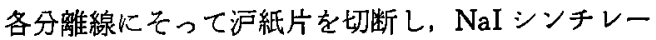
タ上にマゥントし， $\gamma$ 線スペクトルおよび半滅期から 不純物の有無を検討したが，不純物はほとんど検出さ れなかった。

トレーサの量が増大すると分離線の太さがまし，相 互の分離が不充分となるので，このままでは放射化分 析には適用できない。現在担体を入れてもなお分離が 可能となるように厚手沪紙, 汇紙パイルを用いる焦点 クロマトグラフ法を検討中であるが，この方法が可能 となれば全希土類元素の放射化分析が可能となること と期待される。

種々ご教示いたたいた中井敏夫博士に感謝いたしま す。

〔第 6 回放射化学討論会 (1962.10月)にて講演〕

（1963年 2 月19日 受理）

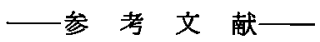

（1）中井敏夫，矢島 聖使，藤井 勲, 亀本堆一郎,

柴 是行：日 化, 82, 197 (1961);

T. Kawashima, M. Osawa, Y. MochizUKI, H. Hamaguchi: Bull. Chem. Soc. Japan, 34, 701 (1961)

J. V. Jakoviev: A/Conf., 15/P/632, (1955), Geneva.

(2) L. R. Bunney, E. C. Freiling, L. D. Mcisaac, E. M. Scadden: Nucleonics, 15, No. 2, 81 (1957); A. K. Lavrukhina, F. I. Pavlotskaya, A.A. PozdnyaKov, I. M. Grechishcheva: Zhur. Neorg. Khim., 3, 82 (1958); Nucl. Sci. Abst., 13807 (1958);

D. C. Stewart: J. Inorg. Nucl. Chem., 4, 131 (1957);

V. V. Nekrasov, E. P. Cherneva, V. A. Bryukhanov, N. N. TUNITSKII: Khromatog., ee Teoriya i Primen., Akad. Nauk SSSR, Trudy 
Vsesoyuz. Soveshchaniya, Moscow, 1958, 47; Chem. Abst., 55, 19417 i (1961);

B. K. ProbrazhenskiI, A. V. Kalyamin, O. M. Lilova: Radiokhimiya, 2, 239 (1960); Chem. Abst., 54, 18020 b (1960);

K. Wolfsberg; Anal. Chem., 34, 518 (1962); 藤井照: 本 誌, 3, No. 3, 186 (1961).

(3) E. Schumacher: Helv. Chim. Acta, 40, 221 (1957) ;
H. J. STREIF ; ibid., 228, 234, 2322 (1957); 品川睦明, 木曾義之：分析化学, 10, 912 (1961);

A. Kolin; "Method of Biochemical Analysis", Vol. VI, p. 259, (1954); J. Chem. Phys., 22, 1628 (1954); 23, 407(1955).

(4) E. Schumacher: Helv. Chim. Acta, 40, 221 (1957);

W. Friedli, E. Schumacher: ibid., 44, 1829 (1961)

\title{
研究猃交
}

\section{1. 水酸化鉄凝集による放射性廃水の除染}

\author{
松村 隆*, 石山稔雄*, 真室哲雄* \\ Decontamination of Radioactive Waste Water \\ by Ferric Hydroxide Flocculation
}

By Takashi MATSUMURA, Toshio ISHIYAMA and Tetsuo MAMURO

\begin{abstract}
Recently flocculators of slurry circulation type have been adopted at various institutes in Japan for the treatment of weakly contaminated radioactive waste water. The mechanism of decontamination in the flocculator is, however, still not enough realized. There are some problems which should be solved in order to make best use of the flocculator. For this purpose, the experiments involving the test flocculations in beakers and in a small flocculator have been carried out in the case of ferric hydroxide flocculation. Among the results obtained, the following facts were considered to be noticeable.

11) The $\mathrm{pH}$ value of the reacting medium has a serious effect on the removal.

(2) As for radioactive ions, the main decontamination process is completed in the stage that the ferric hydroxide particles are formed in the reacting medium. The continuation of strring after this stage gives rise to no further improvement in the removal.

(3) The removal of $\mathrm{Sr}$ is effectively raised by the addition of equivalent or more amount of carbonate ion when the waste water to be decontaminated contains alkali earth metal ions.

(4) Noticeable difference in the removal is not found between the flocculations in a beaker and in a flocculator under the same flocculation conditions.

(5) The main role of slurry circulation type flocculator in the decontamination of radioactive waste water is to clarify the effuluent by dynamical separation of solid from liquid.
\end{abstract}

* 大阪府立放射線中央研究所 (Radiation Center of Osaka Pref.) 